\title{
Effect of late-gestation maternal heat stress on growth and immune function of dairy calves
}

\author{
S. Tao, A. P. A. Monteiro, I. M. Thompson, M. J. Hayen, and G. E. Dahl' \\ Department of Animal Sciences, University of Florida, Gainesville 32611
}

\section{ABSTRACT}

Heat stress during the dry period affects the cow's mammary gland development, metabolism, and immunity during the transition period. However, the effect of late-gestation heat stress on calf performance and immune status is unknown. Our objective was to evaluate the effect of heat stress during the final $\sim 45 \mathrm{~d}$ of gestation on growth and immune function of calves. Calves (17/treatment) were born to cows that were exposed to cooling (CL) or heat stress (HT) during the dry period. Only heifer calves $(\mathrm{CL}, \mathrm{n}=12$; HT, $\mathrm{n}=$ 9) were used in measurements of growth and immune status after birth. Heifer calves were managed under identical conditions. All were fed $3.78 \mathrm{~L}$ of colostrum from their respective dams within $4 \mathrm{~h}$ of birth and were weaned at 2 mo of age (MOA). Body weight (BW) was obtained at weaning and then monthly until 7 MOA. Withers height (WH) was measured monthly from 3 to $7 \mathrm{MOA}$. Hematocrit and plasma total protein were assessed at birth, 1, 4, 7, 11, 14, 18, 21, 25, and $28 \mathrm{~d}$ of age. Total serum IgG was evaluated at 1, 4, 7, 11, $14,18,21,25$, and $28 \mathrm{~d}$ of age, and apparent efficiency of absorption was calculated. Peripheral blood mononuclear cells were isolated at 7, 28, 42, and $56 \mathrm{~d}$ of age, and proliferation rate was measured by ${ }^{3} \mathrm{H}$-thymidine incorporation in vitro. Blood cortisol concentration was measured in the dams during the dry period and in calves in the preweaning period. Gestation length was 4 d shorter for HT cows compared with CL cows. Calves from CL cows had greater BW than calves from HT cows at birth (42.5 vs. $36.5 \mathrm{~kg}$ ). Compared with CL heifers, HT heifers had decreased weaning BW (78.5 vs. $65.9 \mathrm{~kg}$ ) but similar BW (154.6 vs. $146.4 \mathrm{~kg})$ and WH (104.8 vs. $103.4 \mathrm{~cm}$ ) from 3 to $7 \mathrm{MOA}$. Compared with CL, heifers from HT cows had less total plasma protein $(6.3$ vs. $5.9 \mathrm{~g} / \mathrm{dL})$, total serum IgG $(1,577.3$ vs. $1,057.8 \mathrm{mg} / \mathrm{dL})$, and apparent efficiency of absorp-

Received May 4, 2012.

Accepted July 7, 2012.

${ }^{1}$ Corresponding author: gdahl@ufl.edu tion (33.6 vs. 19.2\%), and tended to have decreased hematocrit (33 vs. 30\%). Additionally, CL heifers had greater peripheral blood mononuclear cell proliferation relative to HT heifers (23.8 vs. 14.1 fold). Compared with CL, late-gestation HT did not affect the blood cortisol concentration of dams during the dry period or that of the calves in the preweaning period, but CL calves tended to have increased circulating cortisol at birth $(7.6$ vs. $5.7 \mu \mathrm{g} / \mathrm{dL})$. We conclude that heat stress of the dam during the dry period compromises the fetal growth and immune function of offspring from birth through weaning.

Key words: heat stress, growth, immune function

\section{INTRODUCTION}

Maternal manipulations during gestation affect fetal growth and immunity of neonates. Depending on the stage of gestation, nutrition has profound effects on fetal growth and immune function of the neonate. During late gestation, malnutrition is related to the lower birth weight of offspring, increased incidence of dystocia, and high mortality and morbidity of neonates (Wu et al., 2006). However, ewes with restricted nutrition in early pregnancy birth heavier lambs compared with those with unrestricted nutrition (Funston et al., 2010). In addition to nutrition, other prenatal stressors, such as environmental stress, psychological stress, and social stress, lead to compromised fetal development and postnatal immunity (Merlot et al., 2008; Reynolds et al., 2010).

Heat stress is one of the environmental stressors that dramatically affects the dairy industry. In lactating dairy cattle, heat stress is associated with decreased lactational and reproductive performance and increased disease incidence (Kadzere et al., 2002; Collier et al., 2006). In the dry period, cows exposed to heat stress have decreased milk production in the subsequent lactation and compromised immune function in the transition period (do Amaral et al., 2010, 2011; Tao et al., 2011). In addition to the adverse effects on dams, heat stress during late gestation is also related to lower birth weight of calves, which suggests compromised 
fetal growth (Collier et al., 1982b). However, the effect of prenatal heat stress during the dry period on the postnatal growth of the calves has not been evaluated.

Ambient temperature during late gestation also affects the transfer of passive immunity. During late gestation, piglets from heat-stressed sows have lower circulating IgG compared with those from sows under thermoneutral conditions (Machado-Neto et al., 1987). In contrast, cold stress in late pregnancy increases the IgG absorption of piglets relative to their counterparts from sows in thermoneutrality (Bate and Hacker, 1985). It remains unknown whether maternal heat stress during the dry period has a similar detrimental effect on passive and cellular immune function of neonatal calves. Our hypothesis was that heat stress during the dry period compromises postnatal growth and immune function of dairy calves compared with cooling. The objective of the current study was to evaluate the effect of heat stress during the dry period on the postnatal growth and immune function of dairy calves.

\section{MATERIALS AND METHODS}

\section{Animals and Experimental Design}

This study was conducted at the Dairy Unit and Calf Unit of University of Florida (Hague) from July to November 2010. All treatments and procedures were approved by Institutional Animal Care and Use Committee of University of Florida. Multiparous Holstein cows were dried off at about $45 \mathrm{~d}$ before expected calving date and randomly assigned to 1 of 2 treatments, heat stress (HT) or cooling (CL), based on matureequivalent milk production of the previous lactation. Dry cows were housed in a freestall barn. The stall areas for CL cows were equipped with sprinklers and fans, but those for HT were not (Tao et al., 2011). The treatments of calves were reflected by the treatments of their dams during the dry period. Except for birth weight, only heifer calves (CL: $\mathrm{n}=12$; HT: $\mathrm{n}=9$ ) were used in the current experiment. Heifer calves were removed from their dams immediately after birth and housed and managed in the same manner after birth. Two heifers from HT dams died due to navel infection at 2 wk of age and the data before infection from these 2 calves were incorporated into the statistical analyses.

Colostrum was collected from HT and CL cows within $2 \mathrm{~h}$ after calving, and 40-mL colostrum samples were frozen immediately after collection and stored at $-20^{\circ} \mathrm{C}$. Each calf received $3.78 \mathrm{~L}$ of colostrum from its respective dam within $4 \mathrm{~h}$ of birth by esophageal feeder. After $1 \mathrm{~d}$ of age, calves were fed pasteurized milk. All calves were weaned at 2 mo of age.

\section{Growth Measures and Sample Collection}

All calves ( $\mathrm{n}=34 ; 17$ per treatment) were weighed at birth. Additionally, BW of the heifer calves was obtained at weaning and then monthly until 7 mo of age. Withers height $(\mathbf{W H})$ of heifer calves was measured monthly from 3 to 7 mo of age.

Blood samples were collected via jugular venipuncture from the heifer calves into sodium-heparinized Vacutainer tubes (Becton Dickinson, Franklin Lakes, NJ) at birth (before colostrum feeding), and at 1, 4, $7,11,14,18,21,25$, and $28 \mathrm{~d}$ of age. Samples were immediately put in an ice bath, and hematocrit and plasma total protein were assessed. Additionally, serum samples were collected at $1,4,7,11,14,18,21,25$, and $28 \mathrm{~d}$ of age for total IgG analysis.

\section{Ovalbumin Challenge}

Heifer calves were injected s.c. with $1 \mathrm{~mL}$ of ovalbumin solution containing albumin from chicken egg white $(0.5 \mathrm{mg} / \mathrm{mL}$, Sigma-Aldrich, St. Louis, MO) and adjuvant Quil A $(0.5 \mathrm{mg} / \mathrm{mL}$, Accurate Chemical \& Scientific Corp., Westbury, NY) at 28 and $42 \mathrm{~d}$ of age (Magalhães et al., 2008). Serum samples were collected at $35,42,49$, and $56 \mathrm{~d}$ of age for anti-ovalbumin $\operatorname{IgG}$ analysis.

\section{Peripheral Blood Mononuclear Cell Isolation and Proliferation}

Blood samples were collected from heifer calves at $7,28,42$, and $56 \mathrm{~d}$ of age into sodium-heparinized Vacutainer tubes (Becton Dickinson) and immediately transported to the laboratory at ambient temperature. The procedure of peripheral blood mononuclear cell (PBMC) isolation and proliferation assessment is based on do Amaral et al. (2010). Briefly, samples were centrifuged at $1,000 \times g$ for $30 \mathrm{~min}$ at room temperature $\left(23^{\circ} \mathrm{C}\right)$. The buffy coat between the red blood cells and plasma was transferred to the tubes containing 2 mL of TCM-199 medium (Sigma-Aldrich) and mixed completely. Cell suspension was transferred into tubes containing $2 \mathrm{~mL}$ of Fico/Lite LymphoH (Atlanta Biologicals, Lawrenceville, GA) and followed by centrifugation at $1,000 \times g$ for $30 \mathrm{~min}$ at room temperature. Mononuclear cells were collected and washed before the proliferation assay.

To examine PBMC proliferation, concentrations of PBMC were determined by hemacytometer and adjusted to $1 \times 10^{6}$ cells $/ \mathrm{mL}$ in modified TCM-199 medium supplemented with horse serum (5\%, Atlanta Biologicals), penicillin (200 IU/mL, MP Biomedicals, Solon, $\mathrm{OH})$, streptomycin $(0.2 \mathrm{mg} / \mathrm{mL}$, MP Biomedicals), glu- 
tamine ( $2 \mathrm{~m} M$, Sigma-Aldrich), and $\beta$-mercaptoethanol $\left(10^{-5} M\right.$, Sigma-Aldrich). One hundred microliters of diluted PBMC suspension was added to each well of a 96-well, flat-bottomed sterile plate. Twenty microliters of concanavalin A (ConA, $100 \mu \mathrm{g} / \mathrm{mL}$, Sigma-Aldrich) or Dulbecco's PBS (Sigma-Aldrich) was added to the corresponding ConA or control wells, respectively, in triplicate. All wells were filled with $80 \mu \mathrm{L}$ of modified TCM-199 to reach a final volume of $200 \mu \mathrm{L}$. Plates were incubated for $72 \mathrm{~h}$ at $37^{\circ} \mathrm{C}$ with $5 \% \mathrm{CO}_{2}$. After 48 $\mathrm{h}$ of incubation, $2 \mu \mathrm{L}$ of ${ }^{3}[\mathrm{H}]$-thymidine $(0.2 \mu \mathrm{Ci} / \mu \mathrm{L}$, MP Biomedicals) was added to each well. At the end of the incubation, cells were harvested on a cell harvester (Brandel, Gaithersburg, MD). Stimulation index was calculated as the ratio of the average value of count per minute $(\mathrm{cpm})$ of the ConA wells to the average count per minute value of the control wells.

\section{IgG Analysis}

Total IgG concentration of colostrum and serum samples collected from 1 to $28 \mathrm{~d}$ of age was measured by radial immunodiffusion assay (Triple J Farms, Bellingham, WA) according to the manufacturer's protocol. Briefly, $5 \mu \mathrm{L}$ of colostrum or serum sample was added to the wells in the gel containing anti-bovine IgG antibody and incubated for $27 \mathrm{~h}$ at room temperature and in the absence of light exposure. After incubation, the diameter of the precipitin rings was measured and total IgG concentration calculated based on the linear relationship between diameters squared and total IgG concentration. The interassay $\mathrm{CV}$ of the radial immunodiffusion assay was $3.7 \%$. The apparent efficiency of absorption (AEA) was calculated based on Quigley and Drewry (1998). The total IgG concentration of serum samples collected at $1 \mathrm{~d}$ of age was used to calculate AEA, and serum volume was considered as $9 \%$ of the birth weight.

The anti-ovalbumin IgG concentration was measured by ELISA based on do Amaral et al. (2011). Briefly, flat-bottomed, 96-well high-binding-affinity plates (Immulon 2 HB, Fisher, Pittsburgh, PA) were coated with sodium carbonate-bicarbonate buffer containing $1.4 \mathrm{mg} / \mathrm{mL}$ ovalbumin and incubated at $4^{\circ} \mathrm{C}$ for $48 \mathrm{~h}$. Following incubation, plates were washed 4 times with PBS containing $0.05 \%$ Tween-20 solution (Fisher) and blocked with 1\% BSA (Sigma-Aldrich) solution for $1 \mathrm{~h}$ at room temperature. After washing, the control sera and serum samples were added to the plate based on a quadrant layout and incubated at room temperature for $2 \mathrm{~h}$. At the end of incubation, the plates were washed 4 times, and $100 \mu \mathrm{L}$ of alkaline phosphatase conjugated rabbit anti-bovine IgG solution (Sigma-Aldrich) diluted in Tris buffer solution was added to each well. Following $1 \mathrm{~h}$ of further incubation, the plates were washed 4 times, $80 \mu \mathrm{L}$ of $p$-nitrophenyl phosphate liquid substrate (Sigma-Aldrich) was added to each well, and the plates were incubated for $30 \mathrm{~min}$ at room temperature in the absence of light. Subsequently, the plates were read on an automatic ELISA plate reader (MRX Revelation, Dynex Technologies Inc., Chantilly, VA) at $450 \mathrm{~nm}$ wavelength. The number of animals in each treatment was balanced in each plate. The initial mean and standard deviation were calculated based on the positive controls in the first 3 plates. If the mean of the positive controls in the following plates was outside the range of initial mean $\pm 1.5 \mathrm{SD}$ of the first 3 plates, the whole plate was repeated. The optical density of the respective sample is reported. The interand intraassay CV of the ELISA were 5.8 and $8.1 \%$, respectively.

\section{Cortisol Analysis}

Blood samples from the dams were collected from coccygeal vessel puncture into sodium-heparinized Vacutainers (Becton Dickinson) at dry off and then once daily $(1500 \mathrm{~h})$ at $-32,-18$, and $-7 \mathrm{~d}$ relative to calving and at calving. Upon collection, samples were immediately placed in ice and harvested at 2,619 $\times g$ at $4^{\circ} \mathrm{C}$ for 30 min within $1 \mathrm{~h}$ after collection. After centrifugation, plasma samples were frozen at $-20^{\circ} \mathrm{C}$ until analysis. The circulating cortisol concentration in the serum samples collected from the heifer calves at birth, $1,4,7,14,21,28,35,42,49$, and 56 d of age were also determined. The concentration of cortisol in the plasma and serum was analyzed by RIA using a commercial kit (Coat-A-Count Cortisol kit, Siemens Healthcare Diagnostics, Deerfield, IL). The inter- and intraassay CV of the RIA assay of the plasma from the dams were 10.1 and $9.2 \%$, respectively; those of the serum samples from the calves were 13.8 and $5.0 \%$, respectively.

\section{Statistical Analysis}

Birth weight, weaning weight, BW gain from birth to weaning, colostrum IgG concentration, AEA, and serum cortisol concentration at birth were analyzed by PROC GLM procedure of SAS 9.2 (SAS Institute Inc., Cary, NC) and least squares means \pm standard errors of the mean (LSM $\pm \mathrm{SEM}$ ) are reported. The PROC MIXED procedure of SAS 9.2 was used to analyze the repeated measurements (BW and $\mathrm{WH}$ from 3 to 7 mo of age, hematocrit, plasma total protein, total serum IgG, anti-ovalbumin IgG concentration of serum, PBMC proliferation, plasma cortisol concentration of the dams, and serum cortisol concentration of the calves) and LSM \pm SEM are presented. The SAS 
model included fixed effects of treatment, time, and treatment by time, with calf or cow within the treatment as random effect.

\section{RESULTS}

\section{Data of the Dams}

The descriptive data of the dams during the dry period were reported by Tao et al. (2012). Briefly, all cows were exposed to similar thermal stress (temperaturehumidity index $=78.3$ ) during the dry period, but the cows exposed to HT had greater rectal temperatures $\left(39.3\right.$ vs. $\left.39.0^{\circ} \mathrm{C}\right)$ and respiration rates $(69.2$ vs. 48.3 breath/min) compared with those under CL. Cows exposed to HT consumed less DM (10.2 vs. $11.4 \mathrm{~kg} / \mathrm{d})$ and gained less BW (9.6 vs. $26.0 \mathrm{~kg}$ ) during the dry period and produced less milk (27.7 vs. $34.0 \mathrm{~kg} / \mathrm{d}$ ) until $42 \mathrm{wk}$ postpartum compared with CL cows. Additionally, HT cows had a 4-d-shorter dry period and gestation length compared with CL cows.

\section{$B W$ and $W H$}

Calves born from the HT cows had lower birth weight and weaning weight $(P<0.01$ and $P=0.04$, respectively) compared with calves from CL cows (Table 1). However, treatment had no effect on the BW gain from birth to weaning for heifer calves (Table 1). After weaning, heifers from both groups of cows had similar BW and WH (Table 1).

\section{Hematocrit, Plasma Total Protein, IgG Contents, and PBMC Proliferation}

Heifer calves from the HT cows tended $(P=0.15)$ to have lower hematocrit (Figure 1$)$ and had decreased $(P$ $<0.01$ ) plasma total protein (Figure 1) from birth to $28 \mathrm{~d}$ of age compared with those from CL cows. Heat stress during the dry period did not affect the colostral IgG content (Table 1) but calves exposed to HT in utero had decreased $(P<0.01)$ AEA (Figure 2$)$ and decreased $(P=0.03)$ total IgG concentration in serum (Figure 2) during the first $28 \mathrm{~d}$ of age compared with those cooled in utero. In response to ovalbumin challenge, HT calves had similar $(P=0.60) \mathrm{IgG}$ production relative to $\mathrm{CL}$ calves $(0.41 \pm 0.03$ vs. $0.43 \pm 0.01$ optical density, respectively). Additionally, heifers from the HT cows had decreased $(P=0.05)$ PBMC proliferation during the preweaning period compared with those from CL cows (Figure 3). Independent of treatment, a time effect $(P<0.01)$ was observed: calves had greater PBMC proliferation at $7 \mathrm{~d}$ after birth compared with that at other time points.

\section{Plasma and Serum Cortisol}

During the dry period and at calving, HT cows and CL cows had similar $(0.62 \pm 0.08$ vs. $0.73 \pm 0.07 \mu \mathrm{g} /$ $\mathrm{dL}$, respectively; $P=0.66)$ circulating cortisol levels. We found no overall difference in serum cortisol concentration between HT and CL heifer calves during the preweaning period (Figure 4); however, CL calves tended $(P=0.08)$ to have upregulated circulating cortisol at birth compared with HT calves (Figure 4).

\section{DISCUSSION}

It is important to consider the effectiveness of the heat stress model used in current study, as the examination of neonatal calf growth and performance was predicated on maternal responses during the dry period. All dams were exposed to similar environmental heat stress during the dry period, but the lower rectal temperature and respiration rate of CL cows indicated that they carried less heat load compared with HT cows (Tao et al., 2012). Additionally, as previously reported (do Amaral et al., 2009; Tao et al., 2011), the reduced DMI and BW gain during the dry period, along with compromised lactational performance in the next lactation of HT cows compared with CL cows, provide

Table 1. Birth weight, weaning weight, BW gain from birth to weaning, BW after weaning, and withers height after weaning of calves and colostrum IgG content from dams exposed to either heat stress or cooling during the dry period

\begin{tabular}{lccrr}
\hline Variable & Heat stress & Cooling & SEM & $P$-value \\
\hline Birth weight, kg & 36.5 & 42.5 & 1.2 & $<0.01$ \\
Weaning weight, kg & 65.9 & 78.5 & 4.0 & 0.04 \\
Weaning BW gain, ${ }^{2} \mathrm{~kg}$ & 29.4 & 35.9 & 3.8 & 0.25 \\
BW after weaning, ${ }^{2} \mathrm{~kg}$ & 146.4 & 154.6 & 4.5 & 0.22 \\
Withers height after weaning, ${ }^{3} \mathrm{~cm}$ & 103.4 & 104.8 & 1.0 & 0.33 \\
Colostrum IgG, mg/dL & 8,681 & 7,727 & 726 & 0.36 \\
\hline
\end{tabular}

${ }^{1}$ Weaning BW gain was calculated by subtracting data at weaning by data at birth.

${ }^{2} \mathrm{BW}$ at $3,4,5,6$, and $7 \mathrm{mo}$ of age.

${ }^{3}$ Withers height at $3,4,5,6$, and 7 mo of age. 

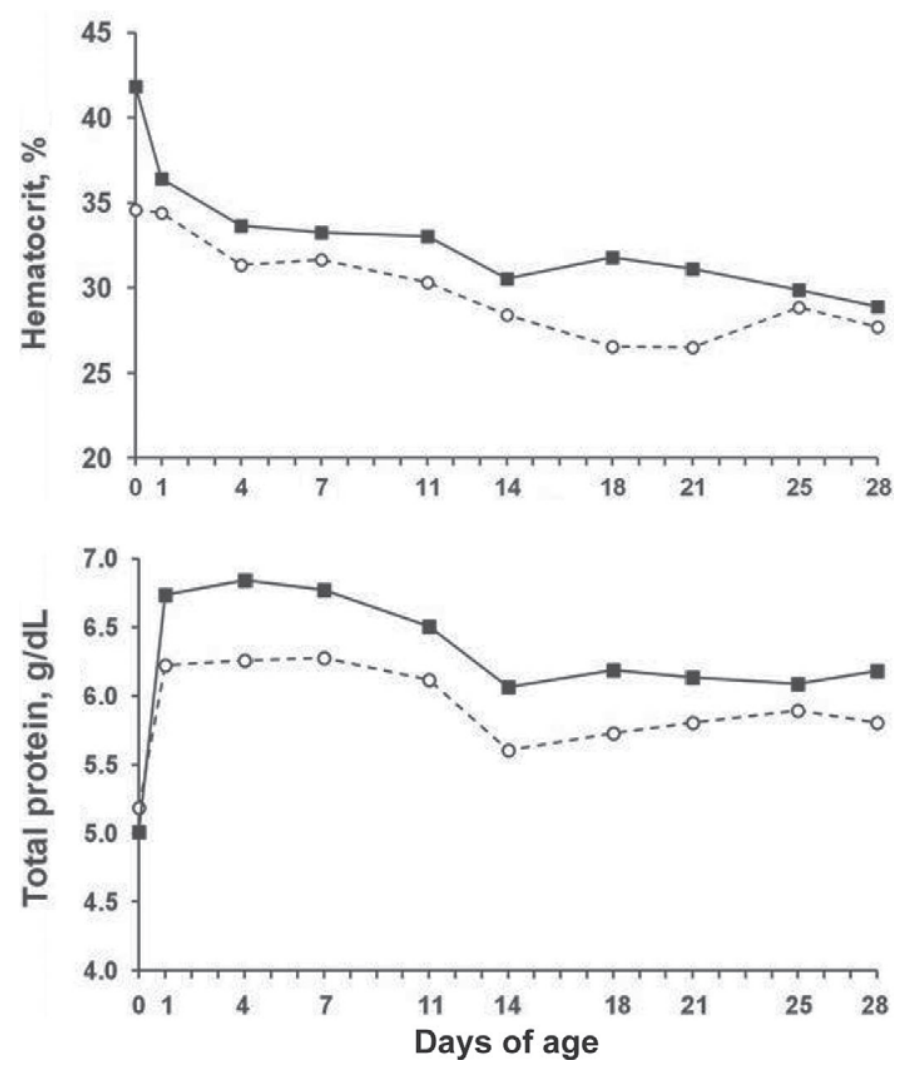

Figure 1. Effect of heat stress and cooling during the dry period on hematocrit and plasma total protein of neonatal calves during the first $28 \mathrm{~d}$ of age. Solid squares ( $)$ represent calves from cows exposed to cooling in the late gestation; open circles $(\bigcirc)$ represent calves from cows in heat stress. Heat stress during the dry period tended to decrease hematocrit $(30.0 \pm 1.6$ vs. $33.0 \pm 1.4 \%$, respectively; $P=0.15)$ and decreased plasma total protein $(5.89 \pm 0.1$ vs. $6.25 \pm 0.1 \mathrm{~g} / \mathrm{dL}$, respectively; $P<0.01$ ) of calves compared with cooling.

solid evidence that the heat-stress model during the dry period in the present experiment was successful.

Similar to other heat-stress studies in late gestation in different species (Brown et al., 1977; Collier et al., 1982b; Tao et al., 2011), newborns from the HT dams had decreased birth weight $(\sim 6 \mathrm{~kg})$ compared with those from the CL dams. Several factors may contribute to compromised fetal growth in late gestation under heat stress. One possible factor is the shorter gestation length of heat-stressed cows, considering that the last 2 mo of gestation is critical to bovine fetal development and accounts for $60 \%$ of the BW gain before birth (Bauman and Currie, 1980). If we assume that the fetus of a Holstein dairy cow has an ADG of $0.5 \mathrm{~kg}$ in the uterus in the last week of gestation (Muller et al., 1975), the 4-d-shorter gestation length in HT cows compared with CL cows in the current study accounts for approximately $33 \%(2 \mathrm{~kg}$ ) of the decreased birth weight of the newborn HT calves. Malnutrition in late gestation may also reduce calf birth weight (Wu et al., 2006) but

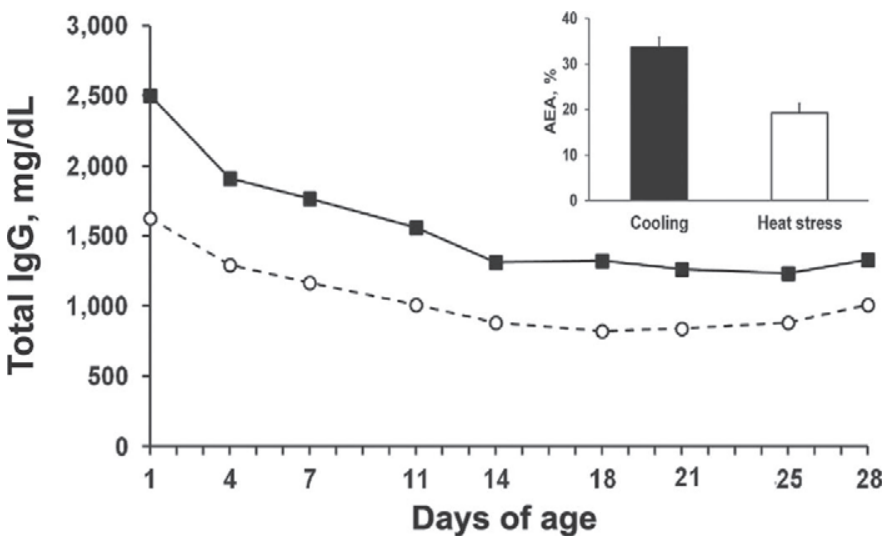

Figure 2. Effect of heat stress and cooling during the dry period on the total serum IgG concentration during the first $28 \mathrm{~d}$ of life and the apparent efficiency of absorption (AEA; inset). Solid squares ( and bar represent calves from cows exposed to cooling during the dry period; open circles $(O)$ and bar represent calves from cows in heat stress. Heat stress during the dry period decreased total serum IgG $(1,057.8 \pm 173.3$ vs. $1,577.3 \pm 149.3 \mathrm{mg} / \mathrm{dL}$, respectively; $P=0.03)$ of calves during the first $28 \mathrm{~d}$ of age compared with cooling. Additionally, the calves exposed to heat stress in utero had lower AEA $(19.2 \pm 2.4$ vs. $33.6 \pm 2.0 \%$, respectively; $P<0.01)$ compared with those cooled in utero.

whether the small decrease in DMI (10-15\%; do Amaral et al., 2009; Tao et al., 2011, 2012) in heat-stressed dry cows could affect fetal growth is questionable. Tudor (1972) reported that feed restriction in the last trimester of pregnancy decreased the calf birth weight of beef cattle; however, in that experiment, the energy

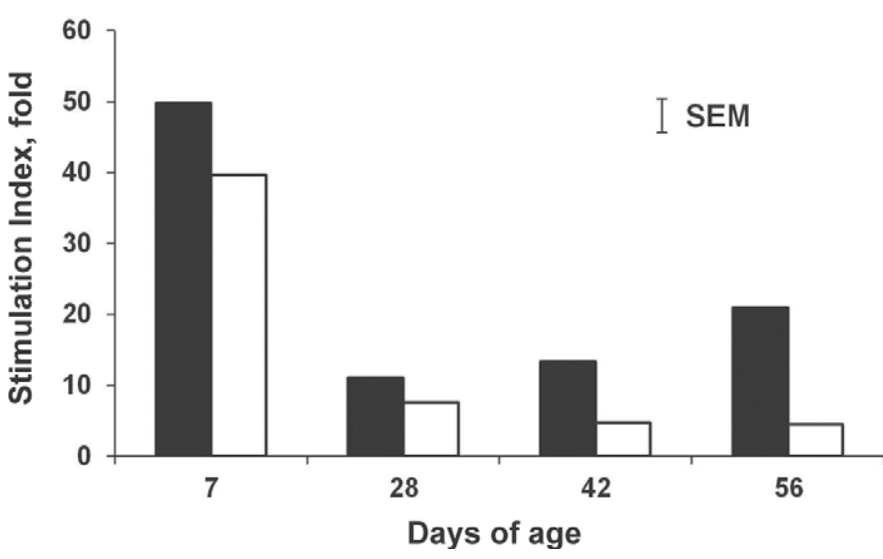

Figure 3. Effect of heat stress and cooling during the dry period on the peripheral blood mononuclear cell (PBMC) proliferation of neonatal calves. Solid bars represent calves from cows exposed to cooling during the dry period and open bars represent calves from cows in heat stress. Standard error of the mean (SEM) is indicated by the line bar inset. Calves from heat-stressed cows during the dry period had decreased stimulation index of proliferation of PBMC $(14.1 \pm 6.0$ vs. $23.8 \pm 4.5$ fold, respectively; $P=0.05$ ) compared with those from cooled cows in the neonatal period. Additionally, calves had higher stimulation index at $7 \mathrm{~d}$ after birth $(P<0.01)$ compared with other time points. 


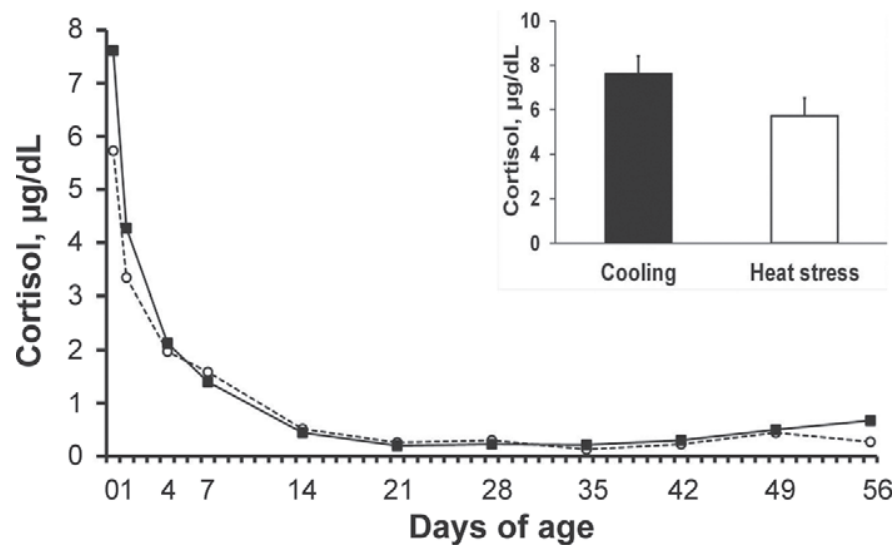

Figure 4. Effect of heat stress and cooling during the dry period on the serum cortisol concentration during preweaning period and at birth (inset). Solid squares (ם) and bar represent calves from cows exposed to cooling during the dry period; open circles $(O)$ and bar represent calves from cows in heat stress. Heat stress during the dry period did not affect cortisol concentration $(1.34 \pm 0.18$ vs. $1.63 \pm$ $0.15 \mu \mathrm{g} / \mathrm{dL}$, respectively; $P=0.73$ ) of calves during the preweaning period compared with cooling. However, at birth, calves exposed to heat stress in utero tended to have lower circulating cortisol $(5.73 \pm$ 0.86 vs. $7.61 \pm 0.75 \mu \mathrm{g} / \mathrm{dL}$, respectively; $P=0.08)$ compared with those cooled in utero.

intake of cows in the low plane of nutrition group was severely restricted such that animals were only fed 3.5 $\mathrm{kg} / \mathrm{d}$ per head of a low energy density diet, whereas cows in the high nutrition group were fed $7 \mathrm{~kg} / \mathrm{d}$ per head of a high energy density diet. On the other hand, the moderate decrease in energy intake in late gestation does not affect calf birth weight in dairy or beef cattle (Hough et al., 1990; Janovick and Drackley, 2010). Indeed, the intrauterine growth retardation (IUGR) caused by late-gestation heat stress in pregnant ewes is independent of restricted nutrition (Brown et al., 1977). In ruminants, heat stress during gestation is associated with decreased uterine blood flow (Reynolds, et al., 1985, 2006) and reduced placental size (Collier et al., 1982a) and function (Collier et al., 1982b; Bell et al., 1989; Early et al., 1991), which in turn limit oxygen diffusion into the fetal circulation (Dreiling et al., 1991) and impair maternal-to-fetal exchange of glucose and amino acids (Reynolds et al., 1985; de Vrijer et al., 2004). To cope with heat stress-related hypoxemia and malnutrition, the ruminant fetus develops a series of endocrine and metabolic adaptations to promote survival at the expense of somatic growth (Yates et al., 2011). In addition to the maternal and placental effects, environmental heat stress may have a direct effect on fetal growth. In heat-stressed pregnant ewes and goats, fetal body temperature rises in parallel to the maternal temperature (Laburn et al., 1992; Faurie et al., 2001), and the maternal heat stress-driven fetal hyperthermia may more directly affect fetal development beyond placental insufficiency (Bell et al., 1989). Thus, the heat stressrelated IUGR and fetal hyperthermia may account for the other $67 \%(4 \mathrm{~kg})$ of decreased fetal growth in HT calves relative to calves from CL cows.

Calves from CL cows were heavier than those from HT cows at weaning; however, the greater weaning weight of CL calves seems to be due to the greater birth weight rather than additional BW gain during the preweaning period. After weaning, the fact that both groups of calves had similar WH and BW suggests a similar rate of growth during the prepubertal period. However, we did not examine whether the body composition of calves was changed by prenatal heat stress in the current experiment. Small-for-gestational-age infants and IUGR lambs have accelerated fat deposition and develop obesity in early life relative to normothermic controls (Morrison et al., 2010; Yates et al., 2011). Whether a similar response occurs in the HT calves remains a question that requires more research because body composition during the prepubertal period can alter mammary gland development of dairy heifers, and thus is closely related to future milk production.

During the first month after birth, HT calves had slightly lower hematocrit levels compared with CL calves. The reason for this phenomenon is unknown, but possibly results from the postnatal adaptation to fetal hypoxia during in utero development, similar to that in the IUGR fetus (Dreiling et al., 1991; Yates et al., 2011). In contrast to other reports (Nardone et al., 1997; Adin et al., 2009), colostral IgG content was not affected by heat stress during the dry period in the current study. Bovine colostrogenesis is under endocrine control and prolactin (PRL) is thought to be involved in the cessation of colostrogenesis (Barrington et al., 2001 ) and to inhibit bovine mammary gland $\operatorname{IgG}_{1}$ receptor expression in vitro and in vivo (Barrington et al., 1997, 1999). Heat stress results in an increase in PRL concentration during the dry period (do Amaral et al., 2009, 2010; Tao et al., 2011). The similar colostral IgG content between HT and CL cows in the current study does not support the concept of an inhibitory effect of PRL on $\mathrm{IgG}_{1}$ receptor expression in the mammary gland. In contrast to studies conducted by Barrington et al. $(1997,1999)$, in which large amounts of PRL were used to mimic the PRL surge at parturition, the hyperthermia-related basal PRL elevation during the dry period, as observed by others (do Amaral et al., 2009, 2010; Tao et al., 2011) was modest and may not be harmful to the IgG transfer. A threshold of PRL concentration during the dry period may exist, below which colostrogenesis will not be influenced. Supporting our theory, different photoperiodic regimens that also influence basal PRL concentration during the dry period (Auchtung et al., 2005) have no effect on mam- 
mary gland immunoglobulin transfer (Morin et al., 2010).

Our results indicate that passive immunity is compromised in calves from HT dams compared with calves from CL dams. The higher total plasma protein and total serum IgG during the first $28 \mathrm{~d}$ of age suggest that $\mathrm{IgG}$ transfer from colostrum to the circulation was greater in CL calves compared with HT calves. After adjustment of birth weight and total colostral IgG intake at birth, the lower AEA of HT calves relative to CL indicates a compromised passive immune transfer of HT calves that is due to an impaired capacity for IgG absorption in the intestine. Similar to our results, the offspring from sows (Machado-Neto et al., 1987) exposed to heat stress in late gestation had lower circulating IgG compared with those from the dams under thermoneutrality. Late-gestation heat stress also slightly decreased the $\operatorname{IgG}$ concentration in neonatal calves after ingestion of pooled colostrum (Stott, 1980); however, that author attributed the lower circulating IgG of heat-stressed calves to the direct effect of thermal stress on neonates at calving and for a short period after calving rather than to the prenatal heat stress of the dams. The underlying mechanisms of the compromised passive immunity by prenatal heat stress are unclear. Glucocorticoid induces gut closure in rats and is suggested as the mediator of enterocyte prematuration in the fetal intestine caused by maternal stress, including hyperthermia, in the pig (MachadoNeto et al., 1987; Merlot et al., 2008). However, piglets from cold-stressed sows in late pregnancy had higher IgG absorption compared with those from the sows in thermoneutrality, despite the observation of increased cortisol levels in cold-stressed sows (Bate and Hacker, 1985). The conflicting results with regard to the relationship between maternal blood cortisol concentration and neonatal $\operatorname{IgG}$ absorption are also observed in dairy cows (Stott, 1980). In the current study, the fact that no difference of circulating cortisol was observed between treatments in the dams during the dry period also suggests that maternal glucocorticoid level may not be a valid explanation for the compromised passive immunity in calves from heat-stressed dams. Moreover, the higher cortisol level of CL calves relative to HT also indicates that glucocorticoid may not be the primary mediator of gut closure of newborn dairy calves as in other species. Another possibility for the decreased IgG transfer in HT calves compared with CL may be the direct effect of colostrum. Besides immunoglobulin, bovine colostrum contains other immune components, growth factors, and hormones that affect gut closure (Sangild, 2003). For example, in heavily exercised athletes, bovine colostrum ingestion improves intestinal integrity and inhibits gut permeability (Marchbank et al., 2011). Further, colostrum from dams with different levels of maternal nutrition has different effects on the passive immunity of neonatal calves (Hough et al., 1990) and lambs (Hodgson et al., 1997). A difference in colostrum composition from HT and CL cows might result in altered IgG transfer to the HT calves.

To our knowledge, this is the first experiment to evaluate the effect of prenatal heat stress on the cellmediated immune response of neonatal calves. During the postnatal period, the lower PBMC proliferation of HT calves indicates a compromised T-lymphocyte response compared with CL calves. Maternal stress during the gestation period decreases thymus size and depresses the T-cell proliferative response to mitogens in neonatal rats (Merlot et al., 2008) and pigs (Tuchscherer et al., 2002). The PBMC proliferation data in the present experiment suggest that the function of lymphocytes is also reduced in the bovine neonate by prenatal stressors such as thermal stress. Regardless of treatment, the higher PBMC proliferation at $7 \mathrm{~d}$ after birth probably results from the effect of maternal leukocytes transferred from the colostrum (Reber et al., 2006) that are capable of full function compared with neonatal lymphocytes. Additionally, maternal leukocytes in colostrum play important roles in the establishment of the innate and adaptive immune systems of neonatal calves (Reber et al., 2008a,b). Thus, the different functionality of maternal leukocytes transferred from colostrum of HT or CL cows may also contribute to the different development of the immune system of the offspring. The fact that both groups of calves had similar antibody production after ovalbumin challenge suggests that prenatal heat stress has no effect on the humoral response of calves during the preweaning period. However, this conclusion is relatively limited because the humoral response in the current study was only evaluated at $4 \mathrm{wk}$ after birth, and altered B-cell function of the offspring in response to prenatal heat stress may have occurred before our measurements.

The similar serum cortisol concentrations of the heifer calves during the preweaning period may be expected because all the calves were exposed to similar management and handling. The higher cortisol concentrations of CL calves at birth relative to HT calves is intriguing and may suggest that calves cooled in utero have a more sensitive hypothalamic-pituitary-adrenal (HPA) axis, compared with HT calves, in response to stress such as parturition. In fetal sheep, plasma estradiol concentration is positively related to the basal circulating ACTH and cortisol in the plasma and to HPA axis sensitivity (Wood, 2005). Heat stress in late gestation of dairy cows markedly decreases placental production of estrone sulfate (Collier et al., 1982b), which may provide the physiological mechanism for the compromised 
fetal HPA axis development in HT calves compared with CL calves, as observed in the current study.

Genomic imprinting, such as epigenetic regulation, may be involved in IUGR and long-term effects in modulating immune function of the offspring from prenatal heat-stressed dams. An abnormal epigenetic profile due to prenatal stress in the human and rat significantly changes placental gene expression profiles, resulting in disturbed placental cell survival and function (Gheorghe et al., 2010; Nelissen et al., 2011) and also affect the gene expression profiles of neonatal tissues, such as brain and liver (Joss-Moore et al., 2010). Similar phenotypic outcomes, including lower birth weight, occur in humans and rats following maternal stress such as fetal hypoxia and malnutrition (Gheorghe et al., 2010), and thus it may be expected that epigenetic modification also played a role in the IUGR of the dairy calves caused by late-gestation heat stress observed in the current study. Immune cells are also the targets of epigenetic regulation (Sanders, 2006; Janson and Winqvist, 2011). In infants, the maternal environment during the prenatal period has a dramatic influence on the fetal development of immune cells through epigenetic modification that, in turn, alters the disease risk in postnatal life (Martino and Prescott, 2011). Thus, it is reasonable to postulate that epigenetic regulation also plays some role in the altered lymphocyte response of neonatal calves to prenatal heat stress. Further studies in this area are required to elucidate the cellular mechanisms involved in prenatal heat stress-related IUGR and immune function modulation in neonatal dairy calves.

\section{CONCLUSIONS}

Heat stress during the dry period of dairy cows decreased calf birth weight and compromised the passive IgG transfer from colostrum and cell-mediated immune function of the calves during the preweaning period. Additionally, prenatal heat stress may affect the HPA axis of the bovine fetus and alter the response to stress in the newborn calf.

\section{ACKNOWLEDGMENTS}

The authors thank the staff of the Dairy Unit and Calf Unit at University of Florida (Hague) for animal care and data collection. Our appreciation extends to S. E. Johnson and A. D. Ealy from University of Florida (Gainesville) for the valuable suggestions. This study was supported by USDA-AFRI Competitive Grant \#2010-85122-20623 to GED.

\section{REFERENCES}

Adin, G., A. Gelman, R. Solomon, I. Flamenbaum, M. Nikbachat, E. Yosef, A. Zenou, A. Shamay, Y. Feuermann, S. J. Mabjeesh, and J. Miron. 2009. Effects of cooling dry cows under heat load conditions on mammary gland enzymatic activity, intake of food water, and performance during the dry period and after parturition. Livest. Sci. 124:189-195.

Auchtung, T. L., A. G. Rius, P. E. Kendall, T. B. McFadden, and G. E. Dahl. 2005. Effects of photoperiod during the dry period on prolactin, prolactin receptor, and milk production of dairy cows. J. Dairy Sci. 88:121-127.

Barrington, G. M., T. E. Besser, C. C. Gay, W. C. Davis, J. J. Reeves, and T. B. McFadden. 1997. Effect of prolactin on in vitro expression of the bovine mammary immunoglobulin $\mathrm{G}_{1}$ receptor. J. Dairy Sci. 80:94-100.

Barrington, G. M., T. E. Besser, C. C. Gay, W. C. Davis, J. J. Reeves, T. B. McFadden, and R. M. Akers. 1999. Regulation of the immunoglobulin $\mathrm{G}_{1}$ receptor: Effect of prolactin on in vivo expression of the bovine mammary immunoglobulin $\mathrm{G}_{1}$ receptor. J. Endocrinol. 163:25-31.

Barrington, G. M., T. B. McFadden, M. T. Huyler, and T. E. Besser. 2001. Regulation of colostrogenesis in cattle. Livest. Prod. Sci. 70:95-104

Bate, L. A., and R. R. Hacker. 1985. Influence of environmental temperature during the late gestation and soon after birth on IgG absorption by newborn piglets. Can. J. Anim. Sci. 65:87-93.

Bauman, D. E., and W. B. Currie. 1980. Partitioning of nutrients during pregnancy and lactation: A review of mechanisms involving homeostasis and homeorhesis. J. Dairy Sci. 63:1514-1529.

Bell, A. W., B. W. McBride, R. Slepetis, R. J. Early, and W. B. Currie. 1989. Chronic heat stress and prenatal development in sheep: I. Conceptus growth and maternal plasma hormones and metabolites. J. Anim. Sci. 67:3289-3299.

Brown, D. E., P. C. Harrison, F. C. Hinds, J. A. Lewis, and M. H. Wallace. 1977. Heat stress effects on fetal development during late gestation in the ewe. J. Anim. Sci. 44:442-446.

Collier, R. J., D. K. Beede, W. W. Thatcher, L. A. Isreal, and C. J. Wilcox. 1982a. Influences of environment and its modification on dairy animal health and production. J. Dairy Sci. 65:2213-2227.

Collier, R. J., G. E. Dahl, and M. J. Vanbaale. 2006. Major advances associated with environmental effects on dairy cattle. J. Dairy Sci. 89:1244-1253.

Collier, R. J., S. G. Doelger, H. H. Head, W. W. Thatcher, and C. J. Wilcox. 1982b. Effects of heat stress during pregnancy on maternal hormone concentrations, calf birth weight and postpartum milk yield of Holstein cows. J. Anim. Sci. 54:309-319.

de Vrijer, B., T. R. H. Regnault, R. B. Wilkening, G. Meschia, and F. C. Battaglia. 2004. Placental uptake and transport of ACP, a neutral nonmetabolizable amino acid, in an ovine model of fetal growth restriction. Am. J. Physiol. Endocrinol. Metab. 287:E1114-E1124.

do Amaral, B. C., E. E. Connor, S. Tao, M. J. Hayen, J. W. Bubolz, and G. E. Dahl. 2009. Heat-stress abatement during the dry period: Does cooling improve transition into lactation? J. Dairy Sci. 92:5988-5999.

do Amaral, B. C., E. E. Connor, S. Tao, M. J. Hayen, J. W. Bubolz, and G. E. Dahl. 2010. Heat stress abatement during the dry period influences prolactin signaling in lymphocytes. Domest. Anim. Endocrinol. 38:38-45.

do Amaral, B. C., E. E. Connor, S. Tao, M. J. Hayen, J. W. Bubolz, and G. E. Dahl. 2011. Heat stress abatement during the dry period influences metabolic gene expression and improves immune status in the transition period of dairy cows. J. Dairy Sci. 94:86-96.

Dreiling, C. E., F. S. Carman 3rd, and D. E. Brown. 1991. Maternal endocrine and fetal metabolic responses to heat stress. J. Dairy Sci. $74: 312-327$.

Early, R. J., B. W. McBride, I. Vatnick, and A. W. Bell. 1991. Chronic heat stress and prenatal development in sheep: II. Placental cellularity and metabolism. J. Anim. Sci. 69:3610-3616. 
Faurie, A. S., D. Mitchell, and H. P. Laburn. 2001. Feto-maternal relationships in goats during heat and cold exposure. Exp. Physiol. $86: 199-204$.

Funston, R. N., D. M. Larson, and K. A. Vonnahme. 2010. Effects of maternal nutrition on conceptus growth and offspring performance: Implications for beef cattle production. J. Anim. Sci. 88 (E-Suppl.):E205-E215.

Gheorghe, C. P., R. Goyal, A. Mittal, and L. D. Longo. 2010. Gene expression in the placenta: Maternal stress and epigenetic responses. Int. J. Dev. Biol. 54:507-523.

Hodgson, J. C., S. M. Rhind, and D. J. Flint. 1997. Influence of maternal nutrition and stress on gut permeability to immunoglobulin in newborn lambs. Biochem. Soc. Trans. 25:339S.

Hough, R. L., F. D. McCarthy, H. D. Kent, D. E. Eversole, and M. L. Wahlberg. 1990. Influence of nutritional restriction during late gestation on production measures and passive immunity in beef cattle. J. Anim. Sci. 68:2622-2627.

Janovick, N. A., and J. K. Drackley. 2010. Prepartum dietary management of energy intake affects postpartum intake and lactation performance by primiparous and multiparous Holstein cows. J. Dairy Sci. 93:3086-3102.

Janson, P. C., and O. Winqvist. 2011. Epigenetics - The key to understand immune responses in health and disease. Am. J. Reprod. Immunol. 66(Suppl. 1):72-74.

Joss-Moore, L. A., D. B. Metcalfe, K. H. Albertine, R. A. McKnight, and R. H. Lane. 2010. Epigenetics and fetal adaptation to perinatal events: Diversity through fidelity. J. Anim. Sci. 88(ESuppl.):E216-E222.

Kadzere, C. T., M. R. Murphy, N. Silaninove, and E. Maltz. 2002. Heat stress in lactating dairy cows: A review. Livest. Prod. Sci. 77:59-91.

Laburn, H. P., D. Mitchell, and K. Goelst. 1992. Fetal and maternal body temperatures measured by radiotelemetry in near-term sheep during thermal stress. J. Appl. Physiol. 72:894-900.

Machado-Neto, R., C. N. Graves, and S. E. Curtis. 1987. Immunoglobulins in piglets from sows heat-stressed prepartum. J. Anim. Sci. 65:445-455.

Magalhães, V. J. A., F. Susca, F. S. Lima, A. F. Branco, I. Yoon, and J. E. P. Santos. 2008. Effect of feeding yeast culture on performance, health, and immunocompetence of dairy calves. J. Dairy Sci. 91:1497-1509

Marchbank, T., G. Davison, J. R. Oakes, M. A. Ghatei, M. Patterson, M. P. Moyer, and R. J. Playford. 2011. The nutriceutical bovine colostrum truncates the increase in gut permeability caused by heavy exercise in athletes. Am. J. Physiol. Gastrointest. Liver Physiol. 300:G477-G484.

Martino, D., and S. Prescott. 2011. Epigenetics and prenatal influences on asthma and allergic airways disease. Chest 139:640-647.

Merlot, E., D. Couret, and W. Otten. 2008. Prenatal stress, fetal imprinting and immunity. Brain Behav. Immun. 22:42-51.

Morin, D. E., S. V. Nelson, E. D. Reid, D. W. Nagy, G. E. Dahl, and P. D. Constable. 2010. Effect of colostral volume, interval between calving and first milking, and photoperiod on colostral IgG concentrations in dairy cows. J. Am. Vet. Med. Assoc. 237:420-428.

Morrison, J. L., J. A. Duffield, B. S. Muhlhausler, S. Gentili, and I. C. McMillen. 2010. Fetal growth restriction, catch-up growth and the early origins of insulin resistance and visceral obesity. Pediatr. Nephrol. 25:669-677.

Muller, L. D., G. L. Beardsley, R. P. Ellis, D. E. Reed, and M. J. Owens. 1975. Calf response to the initiation of parturition in dairy cows with dexamethasone or dexamethasone with estradiol benzoate. J. Anim. Sci. 41:1711-1716.

Nardone, A., N. Lacetera, U. Bernabucci, and B. Ronchi. 1997. Composition of colostrum from dairy heifers exposed to high air temperatures during late pregnancy and the early postpartum period. J. Dairy Sci. 80:838-844.

Nelissen, E. C. M., A. P. A. van Montfoort, J. C. M. Dumoulin, and J. L. H. Evers. 2011. Epigenetics and the placenta. Hum. Reprod. Update 17:397-417.
Quigley, J. D., III, and J. J. Drewry. 1998. Nutrient and immunity transfer from cow to calf pre- and postcalving. J. Dairy Sci. 81:2779-2790.

Reber, A. J., D. C. Donovan, J. Gabbard, K. Galland, M. AcevesAvila, K. A. Holbert, L. Marshall, and D. J. Hurley. 2008a. Transfer of maternal colostral leukocytes promotes development of the neonatal immune system I. Effects on monocyte lineage cells. Vet. Immunol. Immunopathol. 123:186-196.

Reber, A. J., D. C. Donovan, J. Gabbard, K. Galland, M. Aceves-Avila, K. A. Holbert, L. Marshall, and D. J. Hurley. 2008b. Transfer of maternal colostral leukocytes promotes development of the neonatal immune system II. Effects on neonatal lymphocytes. Vet. Immunol. Immunopathol. 123:305-313.

Reber, A. J., A. Lockwood, A. R. Hippen, and D. J. Hurley. 2006 Colostrum induced phenotypic and trafficking changes in maternal mononuclear cells in peripheral blood leukocyte model for study of leukocyte transfer to the neonatal calf. Vet. Immunol. Immunopathol. 109:139-150.

Reynolds, L. P., P. P. Borowicz, J. S. Caton, K. A. Vonnahme, J. S. Luther, C. J. Hammer, K. R. Maddock Carlin, A. T. Grazul-Bilska, and D. A. Redmer. 2010. Developmental programming: The concept, large animal models, and the key role of uteroplacental vascular development. J. Anim. Sci. 88 (E-Suppl.):E61-E72.

Reynolds, L. P., J. S. Caton, D. A. Redmer, A. T. Grazul-Bilska, K. A. Vonnahme, P. P. Borowicz, J. S. Luther, J. M. Wallace, G. Wu, and T. E. Spencer. 2006. Evidence for altered placental blood flow and vascularity in compromised pregnancies. J. Physiol. 572:51-58.

Reynolds, L. P., C. L. Ferrell, J. A. Nienaber, and S. P. Ford. 1985 Effects of chronic environmental heat stress on blood flow and nutrient uptake of the gravid bovine uterus and foetus. J. Agric. Sci. 104:289-297.

Sanders, V. M. 2006. Epigenetic regulation of Th1 and Th2 cell development. Brain Behav. Immun. 20:317-324.

Sangild, P. T. 2003. Uptake of colostral immunoglobulins by the compromised newborn farm animals. Acta Vet. Scand. Suppl $98: 105-122$.

Stott, G. H. 1980. Immunoglobulin absorption in calf neonates with special considerations of stress. J. Dairy Sci. 63:681-688.

Tao, S., J. W. Bubolz, B. C. do Amaral, I. M. Thompson, M. J. Hayen, S. E. Johnson, and G. E. Dahl. 2011. Effect of heat stress during the dry period on mammary gland development. J. Dairy Sci. 94:5976-5986.

Tao, S., I. M. Thompson, A. P. A. Monteiro, M. J. Hayen, L. J. Young, and G. E. Dahl. 2012. Effect of cooling heat-stressed dairy cows during the dry period on insulin response. J. Dairy Sci. 95:50355046.

Tuchscherer, M., E. Kanitz, W. Otten, and A. Tuchscherer. 2002. Effects of prenatal stress on cellular and humoral immune responses in neonatal pigs. Vet. Immunol. Immunopathol. 86:195-203.

Tudor, G. D. 1972. The effect of pre- and post-natal nutrition on the growth of beef cattle. 1. The effect of nutrition and parity of the dam on calf birth weight. Aust. J. Agric. Res. 23:389-395.

Wood, C. E. 2005. Estrogen/hypothalamus-pituitary-adrenal axis interactions in the fetus: The interplay between placenta and fetal brain. J. Soc. Gynecol. Investig. 12:67-76.

Wu, G., F. W. Bazer, J. M. Wallace, and T. E. Spencer. 2006. Boardinvited review: Intrauterine growth retardation: Implications for the animal sciences. J. Anim. Sci. 84:2316-2337.

Yates, D. T., A. S. Green, and S. W. Limesand. 2011. Catecholamines mediate multiple fetal adaptations during placental insufficiency that contribute to intrauterine growth restriction: Lessons from hyperthermic sheep. J. Pregnancy 2011:740408. http://dx.doi. org/10.1155/2011/740408. 